\title{
HUMANE ETHICS \\ AND THE SURVIVAL OF THE HUMAN SPECIES
}

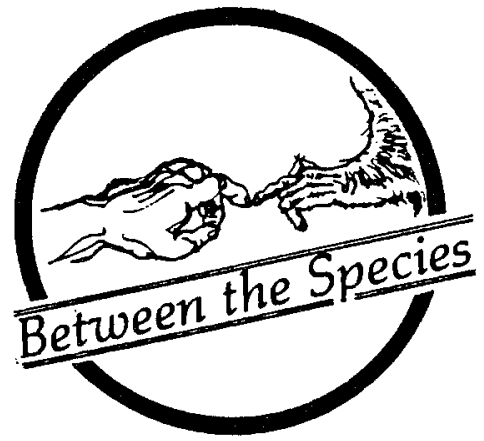

\author{
MICHAEL W. FOX
}

The Humane society of the United States

What distinguishes one species from others are its unique biological characteristics. When certain characteristics change within a species, a new sub-species or race develops. And when these biological characteristics become even more distinctive, a new species arises.

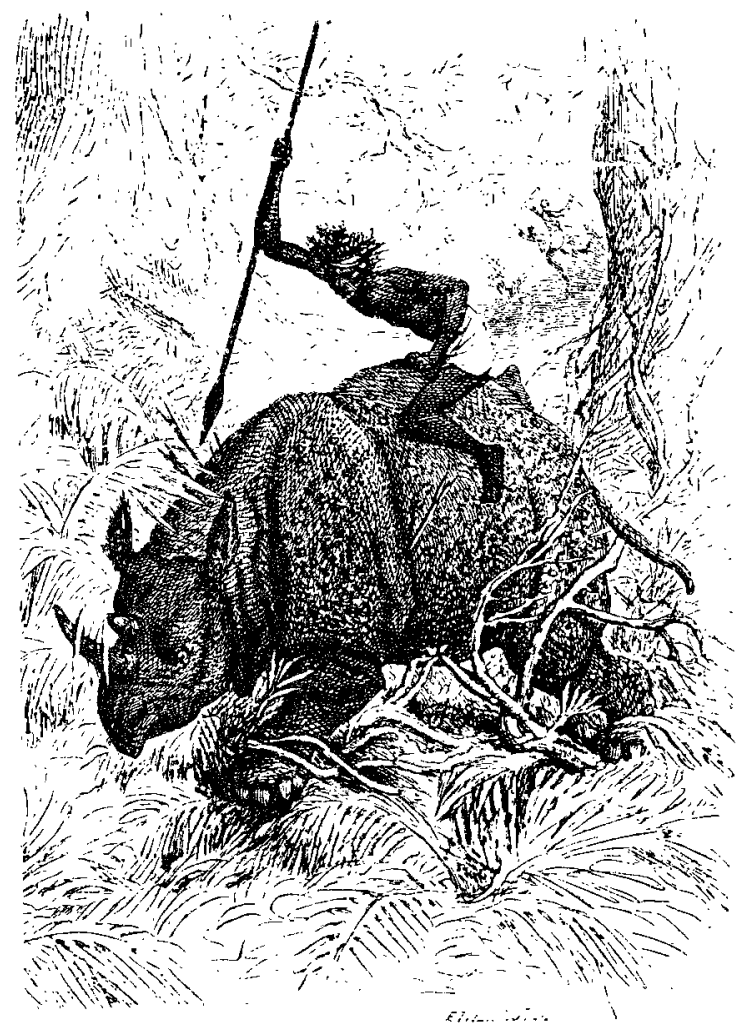

Cultural and ideological characteristics account for marked differences within the human race, which are analogous to the biological differences between animals that lead to speciation: the evolution of various species. Thus, by analogy, as some animal species become extinct and new species develop, so some cultures and ideologies become extinct and new ones arise. While the external, physical characteristics of Homo sapiens remain relatively unchanged over millenia, social, cultural, technological, and ideological changes can be dramatic. It is as though a new species has arisen. Relatively unchanged external, physical appearance maintains the illusion that people are no different today fundamentally than they were, say, 5,000 years ago. However, social, cultural, technological, and ideological changes make it seem as though we are progressively evolving toward some final point of perfection, as some optimists believe.

But I believe that there is no final point of perfection in evolution, since all of life is in a constant state of adaptation and transformation. I also believe that as animal species can become extinct biologically, so the human species can become extinct as it loses those essential characteristics that make it human. These include ethical sensibility, empathetic sensitivity, and compassion toward all creatures. In other words, while Homo sapiens may continue to exist biologically in a physical form that remains relatively unchanged, the psychological and spiritual characteristics of the human race could change so dramatically that within a few generations the equivalent of a new species arises.

I believe that the human species is endangered today and will become extinct as

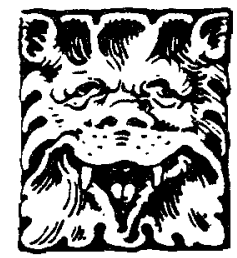

COMMENT 
something less than human, yet in human form, evolves: a new species that is ruthlessly rational, objective, egotistical, emotionally controlled and controlling, and incapable of distinguishing sentimentality from empathy and compassion, and ethical sensibility from self-serving moralizations and rationalizations.

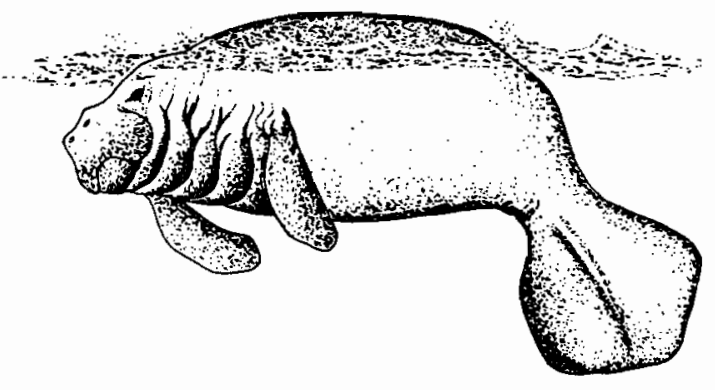

While this new species may annihilate itself in a thermo-nuclear conflagration as warring factions compete for dwindling world resources, they are more likely to turn the Earth into an industrialized wasteland. Each generation will have greater and greater difficulty in finding new technological "fixes," medical and other "advances" to help them adapt to a diseased, polluted, and depleted environment. People will become the prisoner of their own controls as a result of their anxious quest to control the world and of their selfish abuse of their power of dominion over God's creation, Nature and the animal kingdom.

Already this new species is in our midst today, looking deceptively human inside white laboratory coats, business suits, and military uniforms. But behind these masks is a being that is the most dangerous creature on Farth, for as it gains control of the world to secure its own survival, it does so in violation of the rights of others and at the expense of animal species which, along with that species which was once human, are becoming extinct.

The anima mundi, the soul of the Earth, is being destroyed as nature is turned into an industrialized wasteland. Likewise, the human soul is being destroyed as those qualities that make us human become atrophied. And lacking soul, there can be no empathy and respect for animals. Hence, they, like the Earth, are treated as though they are not ensouled beings worthy of equal and fair consideration.

It is a spiritual and survival imperative for human--humane--beings to realize that the extinction of the animal kingdom and annihilation of the natural world will mean their own extinction also. They will be supplanted by an inhumane species that looks human but is not. The hope for survival is to keep alive in each generation those qualities that make us human, especially compassion, respect for each other's and animals' rights, and reverence for Nature, and the ethical and spiritual principles and perceptions that arise from them.

\section{ANIMALS. Do they matter?}

An exciting new awareness is unfolding about our relationship with animals and the rest of the natural world. Read about it in THE ANIMALS' AGENDA.

\section{THE ANIMALS' AGENDA give:} you news; views and articles about animal rights, welfare and protection. and about the people who are making animal rights one of the major issues of the ' $8(1)$ 's. A WHOLE MOVEMENT
IN (ONES MAGAZINE FRE!

\begin{tabular}{|l} 
IN (ONE MAGAZINE \\
$\square$ YES, Sign me \\
up for THE \\
ANIMALS \\
AGENDA \\
1 yr. $\$ 15.00$ \\
[ 2 yrs. $\$ 27.50$ \\
Li 3 yrs. $\$ 37.50$
\end{tabular}

Here's 52 - Send me a sample copy and more information

NAME

STREET

CITY_ STATE___Z_H

THE ANIMALS' AGENDA

P.O. Box 5234, Westpon, CT (fi881 